\title{
Measurement of steroid concentrations in brain tissue: methodological considerations
}

\author{
Matthew D. Taves ${ }^{1,2}{ }^{*}$, Chunqi Ma ${ }^{1}$, Sarah A. Heimovics ${ }^{1}$, Colin J. Saldanha ${ }^{3,4}$ and Kiran K. Soma ${ }^{1,2,5}$ \\ 1 Department of Psychology, University of British Columbia, Vancouver, BC, Canada \\ ${ }^{2}$ Department of Zoology, University of British Columbia, Vancouver, BC, Canada \\ ${ }^{3}$ Department of Biological Sciences, Lehigh University, Bethlehem, PA, USA \\ ${ }^{4}$ Program in Cognitive Science, Lehigh University, Bethlehem, PA, USA \\ ${ }^{5}$ Graduate Program in Neuroscience, University of British Columbia, Vancouver, BC, Canada
}

\section{Edited by:}

Hubert Vaudry, University of Rouen,

France

Reviewed by:

Gustavo M. Somoza, Instituto de Investigaciones

Biotecnologicas-Instituto Tecnologico de Chascomus, Argentina

Stanko S. Stojilkovic, National

Institutes of Health, USA

*Correspondence:

Matthew D. Taves, Department of Psychology, University of British

Columbia, 2136 West Mall, Vancouver,

BC, Canada V6T $1 Z 4$

e-mail:taves@zoology.ubc.ca
It is well recognized that steroids are synthesized de novo in the brain (neurosteroids). In addition, steroids circulating in the blood enter the brain. Steroids play numerous roles in the brain, such as influencing neural development, adult neuroplasticity, behavior, neuroinflammation, and neurodegenerative diseases such as Alzheimer's disease. In order to understand the regulation and functions of steroids in the brain, it is important to directly measure steroid concentrations in brain tissue. In this brief review, we discuss methods for the detection and quantification of steroids in the brain. We concisely present the major advantages and disadvantages of different technical approaches at various experimental stages: euthanasia, tissue collection, steroid extraction, steroid separation, and steroid measurement. We discuss, among other topics, the potential effects of anesthesia and saline perfusion prior to tissue collection; microdissection via Palkovits punch; solid phase extraction; chromatographic separation of steroids; and immunoassays and mass spectrometry for steroid quantification, particularly the use of mass spectrometry for "steroid profiling." Finally, we discuss the interpretation of local steroid concentrations, such as comparing steroid levels in brain tissue with those in the circulation (plasma vs. whole blood samples; total vs. free steroid levels). We also present reference values for a variety of steroids in different brain regions of adult rats. This brief review highlights some of the major methodological considerations at multiple experimental stages and provides a broad framework for designing studies that examine local steroid levels in the brain as well as other steroidogenic tissues, such as thymus, breast, and prostate.

Keywords: corticosterone, estradiol, mouse, songbird, testosterone

\section{INTRODUCTION}

Steroids play many important physiological roles in the brain and influence brain development, behavior, cognition, neuroplasticity, and neuroinflammation (Baulieu, 1998; Sakamoto et al., 2001b; Sorrells and Sapolsky, 2009). In addition to steroids that enter the brain from the periphery, steroids are synthesized within the brain itself ("neurosteroids"; Corpéchot et al., 1981). Neurosteroids can be synthesized de novo from cholesterol or from circulating inactive precursors (Compagnone and Mellon, 2000; Schmidt et al., 2008; Do Rego et al., 2009). Because the brain is both a producer and a target of steroids, it is of great interest and utility to measure endogenous steroid levels in specific brain regions. Measurement of local steroid levels allows for comparisons among different brain regions, as well as comparisons between brain and blood. Such comparisons are useful in determining which tissues are synthesizing or metabolizing steroids (Schmidt and Soma, 2008; Hojo et al., 2009; Konkle and McCarthy, 2011). Indeed, the presence of high pregnenolone and dehydroepiandrosterone (DHEA) concentrations in the brain, and low concentrations in the plasma, of gonadectomized and adrenalectomized rats was the first evidence that suggested steroid production in the brain (Corpéchot et al., 1981). High local steroid levels, along with studies of steroidogenic enzyme mRNA, protein, and activity in the brain, have demonstrated that the brain functions as a steroid-synthetic organ (Schmidt et al., 2008; Taves et al., 2011).

The conceptual leap that permitted the brain to be considered a source (rather than merely a target) of steroid hormones meant that measuring peripheral steroid levels in the blood was no longer sufficient for understanding steroid actions in the brain. Determining the steroid level required for induction of a particular behavior, for example, involves addressing the contributions of steroids of both peripheral and central origin. To add to the complexity, peripheral steroids that enter the brain are converted into both inactive metabolites and more potent steroids (Mellon and Griffin, 2002). Since the expression and activity of steroidogenic enzymes determines the steroidal milieu of different brain regions, understanding the distribution and regulation of steroidogenic enzymes in the central nervous system is a major 
step forward in estimating local steroid concentrations (Do Rego et al., 2009). Indeed, the majority of papers on this topic have measured steroidogenic enzymes in the brain, rather than the products of these enzymes (i.e., the steroids themselves). However, the aggregate result of steroid synthesis and metabolism in the brain and steroid uptake from the blood can only be determined via empirical measurements of steroid concentrations in discrete brain regions.

Measuring steroids in brain tissue presents a number of technical challenges. These challenges include: the high lipid content of brain tissue (requiring good sample preparation to avoid assay interference; Rash et al., 1980); the high spatial heterogeneity of the brain (resulting in small tissue amounts; Charlier et al., 2010); low steroid concentrations, in some cases (Gomez-Sanchez et al., 2005); ability of steroids to freely diffuse across cell membranes (due to their hydrophobic nature); unique steroids that are absent in the periphery (e.g., 17 $\alpha$-estradiol; Toran-Allerand et al., 2005); and rapid changes in steroid production and metabolism (Balthazart and Ball, 2006). In this brief review, we discuss methodological considerations that address or reduce these technical challenges, and we also discuss the interpretation of tissue steroid concentrations. For a more general and comprehensive guide to steroid analysis, we direct readers to the excellent text edited by Makin and Gower (2010). Although here we focus on steroids in brain tissue, the general principles discussed are also relevant for the measurement of steroids in various other organs and tissues (Taves et al., 2011).

\section{SAMPLE COLLECTION \\ STUDY SPECIES}

Building upon the initial description of neurosteroid synthesis in the mammalian brain (Corpéchot et al., 1981; Le Goascogne et al., 1987), subsequent work has identified neurosteroid synthesis across vertebrate species, including fish (Forlano et al., 2001; Sakamoto et al., 2001a; Diotel et al., 2011), amphibians (MensahNyagan et al., 1996; Takase et al., 1999; Matsunaga et al., 2004; Bruzzone et al., 2010), and birds (Tsutsui et al., 2000; Soma et al., 2004; London et al., 2006; Saldanha et al., 2011). The high levels of steroidogenic enzyme expression and activity (and corresponding high levels of steroids) in the brains of non-mammalian species are a major advantage in the study of neurosteroids (Goodson et al., 2005; Do Rego et al., 2009; Saldanha et al., 2009; Diotel et al., 2010). In addition, because many birds are diurnal and terrestrial, they are highly amenable to field work. This allows studies of neurosteroids in a natural and ecologically relevant context and studies of how neurosteroids regulate natural behaviors (Soma and Wingfield, 2001; Soma, 2006; Soma et al., 2008; Newman and Soma, 2009; Pradhan et al., 2010b). Comparative work has shown that neurosteroid production is conserved across vertebrates, and thus appears to be a general characteristic of the vertebrate brain (Callard et al., 1978), including the human brain (Stoffel-Wagner, 2001; Yu et al., 2002).

\section{INDIRECT MEASUREMENT OF BRAIN STEROID LEVELS}

There are several strategies to indirectly assess brain steroid levels. Some of these approaches allow for repeated sampling from individual subjects, either in different contexts or in real-time during experiments. One method of indirectly estimating brain steroid levels involves collecting blood leaving the brain (i.e., from the jugular vein) and comparing this to blood from another source (e.g., carotid artery, brachial vein, or heart). If steroid levels are higher in blood from the jugular vein, then this suggests production of these steroids in the brain (Schlinger and Arnold, 1992, 1993; Saldanha and Schlinger, 1997; Chin et al., 2008; Newman et al., 2008b; Charlier et al., 2009; Newman and Soma, 2011). To our knowledge, this approach has only been used in studies of songbirds but might prove useful in other species as well. Clearly, this approach is indirect and cannot reveal the absolute concentrations of steroids in specific brain regions. Nonetheless, this approach can be useful for determining relative changes in whole brain steroid production, and it permits repeated sampling from subjects. However, note that stress can rapidly alter steroid concentrations in the jugular blood (Newman et al., 2008b).

Cerebrospinal fluid (CSF) can also be used to indirectly estimate the neural steroidal milieu (Guazzo et al., 1996). For example, in humans, CSF steroid levels are altered in patients with neurological diseases such as Alzheimer's disease (Kim et al., 2003). However, collecting CSF samples of sufficient volume from small animals (e.g., mice) is a more difficult obstacle.

Microdialysis allows quantification of changing steroid levels in a specific brain region (Saleh et al., 2004; Droste et al., 2008; Remage-Healey et al., 2008). Artificial CSF is perfused into the brain through a microdialysis probe, and dialysate is collected across a membrane. This extremely powerful technique can be used to measure temporal changes in steroid levels at a specific location in the brain of a freely behaving subject. Another advantage is that subjects require minimal handling at the time of sample collection. A disadvantage is that steroid levels are measured in only a single region at a time. Moreover, steroid recoveries across the dialysis membrane in vitro are generally low (often <10\%; e.g., Remage-Healey et al., 2008), and this affects the minimum time windows required for dialysate collection (often 5-30 $\mathrm{min}$ ) in order to have a detectable amount of steroid. Steroid recoveries across the dialysis membrane in vivo are very difficult to estimate, and thus one cannot calculate absolute steroid levels in the extracellular fluid. Lastly, microdialysis probe insertion causes injury to the brain, which may induce neurosteroid synthesis (Garcia-Segura et al., 2001; Saldanha et al., 2009). This must be considered when interpreting the results.

Many studies have investigated steroids produced by brain tissue in vitro. These studies can examine steroid synthesis from radiolabeled precursors, as well as measure endogenous steroid levels in the conditioned medium and cultured tissue (organotypic brain slices, minces, or dissociated cells; Gomez-Sanchez et al., 1997; Holloway and Clayton, 2001; Hojo et al., 2004; Kretz et al., 2004; Munetsuna et al., 2009; Higo et al., 2011). These in vitro studies are very useful for investigating the regulation and functions of neurosteroids. However, the levels of steroids produced in vitro cannot directly reveal the levels of steroids in the brain in vivo (Schlinger et al., 1994; Saldanha et al., 2009). Moreover, creating brain slices or dissociating cells causes tissue injury and thus might affect steroid production. 


\section{EUTHANASIA}

To directly measure steroid levels in various brain regions of animals, the brain must be collected after euthanasia of the subjects. Importantly, the method of euthanasia can affect steroid concentrations in the brain. The appropriate method of euthanasia should minimize stress and discomfort of the subjects as well as minimize changes in brain steroid levels. These considerations will vary depending on the nature of the experiment and the study species. A further consideration is whether blood should be collected and, if so, whether blood should be collected immediately before or after euthanasia and how and from where blood should be collected (Newman et al., 2008b).

Euthanasia is commonly performed by an overdose of an anesthetic. This method allows the animal to be subsequently perfused with saline (to remove blood from the brain; see below). However, inducing a loss of consciousness via anesthetic requires an alteration of neural activity (MacLusky, 2009), which might affect brain steroid levels. The effects of anesthesia on brain steroids can be specific to the anesthetic agent used. In rabbits, isoflurane or halothane gas anesthesia may rapidly increase plasma corticosterone and cortisol levels (González-Gil et al., 2006). However, in rats, carbon dioxide anesthesia for up to 2 min does not affect plasma corticosterone levels (Hackbarth et al., 2000). To our knowledge, no studies have examined the acute effects (within 2-3 min) of inhalant anesthesia on brain steroid measurements. Effects of injectable anesthetics on brain steroids also appear to be specific to the anesthetic used. For example, brain progestin levels are increased by injection of chloral hydrate or urethane, but brain progestin levels are decreased by pentobarbital, ketamine, or clonazepam (Korneyev et al., 1993a). Dramatic changes occur within $30 \mathrm{~min}$, and in some cases within $10 \mathrm{~min}$ (Korneyev et al., 1993a). Again, however, we know of no studies examining the acute effects of injectable anesthetics on brain steroid measurements. Thus, when necessary and appropriate, anesthesia should be performed as rapidly as possible and with a method that minimizes changes in steroid levels. The stressors of handling and transfer into a novel cage for anesthesia may themselves cause rapid steroid changes. These stressors can be minimized by regular handling in the days prior to anesthesia or by administration of anesthesia in the home cage (e.g., Reburn and Wynne-Edwards, 2000).

Physical euthanasia without anesthesia does not depend on chemical alteration of nervous system activity (Karmarkar et al., 2010), and examples include decapitation or cervical dislocation without prior anesthesia (American Veterinary Medical Association, 2007). Loss of consciousness following decapitation is rapid (within seconds) and humane (Holson, 1992; Rijn et al., 2011), although some brain electrical activity can be recorded for up to 1 min (Rijn et al., 2011), which could potentially alter steroid levels. Rapid cooling of brain tissue might prevent such neurochemical changes, if present.

Euthanasia can also be performed by head-focused microwave irradiation, which rapidly heats the brain to cause extremely rapid loss of consciousness while maintaining physical integrity (Murphy, 2010). Heat inactivation stops enzymatic activity, thus rapidly halting lipid metabolism (Murphy, 2010) and changes in protein phosphorylation (O'Callaghan and Sriram, 2004), which otherwise continue after physical euthanasia. Focused microwave irradiation is thus potentially useful for preventing continued steroid metabolism and has been used in a few studies of brain steroid levels (e.g., Korneyev et al., 1993a,b; Barbaccia et al., 1996; Concas et al., 2000).

To our knowledge, no studies have directly compared different methods of euthanasia and their effects on brain steroid levels. Such data would be very useful for researchers selecting the best method of euthanasia for an experiment.

\section{PERFUSION WITH PHYSIOLOGICAL SALINE}

In some studies, it may be important to remove blood contamination from the brain. This can be achieved via transcardial perfusion with physiological saline (following anesthesia). For example, saline perfusion is often performed prior to tissue fixation for immunohistochemistry. Also, removal of blood contamination might give a more accurate estimate of steroid concentrations in the brain tissue (i.e., without steroids in the blood; Taves et al., 2010). This issue has been experimentally examined in rats, mice, and songbirds. In neonatal rats and adult mice, saline perfusion has no effects on brain $17 \beta$-estradiol and corticosterone levels, respectively (Amateau et al., 2004; Little et al., 2008). However, in adult zebra finches, saline perfusion increases brain corticosterone levels, decreases brain DHEA levels, and increases brain $17 \beta$-estradiol levels in a region-specific manner, possibly due to rapid effects of ischemia (Taves et al., 2010). Such steroid changes might be minimized by perfusion with oxygenated artificial CSF. Thus, when necessary, perfusion should be performed as rapidly as possible. Furthermore, because saline perfusion does not cause a global decrease in brain steroid levels, blood contamination $(\sim 1 \%$ of brain, v/w) does not appear to significantly affect brain steroid measurements (Taves et al., 2010). Prior to an experiment, validations should be performed to ensure that saline perfusion does not affect brain steroid levels.

\section{DISSECTION}

For measurement of brain steroid concentrations, nearly all studies have used gross dissection of tissue blocks that contain brain regions of interest (e.g., Butte et al., 1972; Caruso et al., 2008; Croft et al., 2008; Newman and Soma, 2009; Brummelte et al., 2010). To do this, the brain can be briefly cooled on wet ice, and then a scalpel blade is used to cut blocks of tissue based on their position relative to major neuroanatomical landmarks (e.g., midline, ventricles). Large areas, such as the cerebral cortex or hippocampus, can be subdivided as appropriate. Typically, tissue blocks are then frozen on dry ice and stored at $-80^{\circ} \mathrm{C}$. Such tissue blocks are relatively large, which increases the likelihood that steroids will be detectable in the sample and might also allow a greater number of steroids to be measured in a single sample. The major disadvantage of gross dissection is the loss of neuroanatomical specificity. Additionally, gross dissection by hand could increase the variability in the size of tissue samples across subjects.

Microdissection of specific brain regions allows for a higher degree of spatial specificity of brain steroid measurements (Magariños et al., 1989). Recently, microdissection of brain nuclei using the Palkovits punch technique (Palkovits, 1973; de Kloet, 2006) has been used for measurement of brain steroid concentrations (Charlier et al., 2010, 2011). Here, the whole brain is immediately 
frozen on powdered dry ice and stored at $-80^{\circ} \mathrm{C}$. The brain is then covered in an embedding matrix intended for sectioning at a relatively warm temperature (e.g., Tissue-Tek O.C.T.), and brain sections $(200-500 \mu \mathrm{m})$ are cut on a cryostat at -12 to $-10^{\circ} \mathrm{C}$. The sections should be kept frozen at all times. Locations of specific brain nuclei can be determined using major neuroanatomical landmarks and a brain atlas. Sections containing nuclei of interest are mounted onto glass microscope slides, and cannulae (kept at $-10^{\circ} \mathrm{C}$ or colder) are used to punch out tissue from the sections. The sections can then be stained with a Nissl stain to verify the locations of the punches (Charlier et al., 2010).

Microdissection has several advantages over gross dissection. Since the whole brain is frozen immediately after removal from the cranium, the amount of postmortem steroid metabolism is reduced. Additionally, microdissection allows for more precise targeting of specific brain nuclei. Finally, tissue samples are of a uniform size, which reduces between-subject variability in the amount of brain tissue per sample. A disadvantage of microdissection is that the tissue samples can be small (often $<1 \mathrm{mg}$ ), and thus ultrasensitive assays are necessary to measure steroids in such small samples (Charlier et al., 2010). If the assays are also very precise, then samples need not be measured in duplicate (i.e., can be measured as singletons), which can be useful when the amount of sample is limited (Charlier et al., 2011). Note also that intermediate levels of spatial specificity can be achieved using a "brain matrix" (e.g., Ted Pella,\#15007; Soma et al., 2005) or a tissue chopper (e.g., Ted Pella,\#10180), followed by additional dissection with a scalpel or cannula.

Regardless of the method used to collect brain tissue, the amount of steroid in each sample must be corrected for the amount of tissue (typically wet weight in grams; see below). With gross dissection, each sample must be weighed on a microbalance. With Palkovits punch microdissection, however, all samples are of known thickness and diameter, and thus are of similar weight (Charlier et al., 2011). For example, when using a 1-mm-diameter cannula (Fine Science Tools, \#18035-01) on $300 \mu \mathrm{m}$ song sparrow brain sections, we have empirically determined that one brain punch has a mean wet weight of $0.245 \mathrm{mg}$ (and protein content of $0.02 \mathrm{mg}$ ), with very little variation.

\section{STEROID EXTRACTION \\ TISSUE HOMOGENIZATION}

Once brain tissue samples have been collected, steroids must be extracted before they can be quantified (Newman et al., 2008a). This is especially critical in tissues such as brain that have very high lipid content, since lipids can interfere with steroid measurement (Rash et al., 1980). Prior to steroid extraction, tissue samples should be homogenized. To reduce potential metabolism of steroids in the tissue, tissue homogenization can be performed in ice-cold water and followed immediately by addition of an organic solvent such as methanol. Homogenization can also be performed in a water/methanol solution. Homogenization can be performed with a microcentrifuge tube and fitted pestle (Charlier et al., 2010), an electric hand-held homogenizer (e.g., Fisher Scientific PowerGen 125, \#3396001; Newman and Soma, 2009; Taves et al., 2010), or bead mill homogenizer (e.g., Omni Bead Ruptor 24,\#19-101). We have found that each of these homogenization techniques results in a similar mean steroid concentration, although the bead mill homogenizer increases sample throughput and appeared to produce less variability across samples in a pilot study (unpublished results). Bead mill homogenization also prevents cross-sample contamination. To further ensure disruption of cells, tissue can be homogenized in lysis buffer (Konkle and McCarthy, 2011), or homogenized samples can be placed in a sonicator.

\section{STEROID EXTRACTION}

Following tissue homogenization, steroids must be extracted to separate them from other components of the brain sample, especially other lipids. Liquid-liquid extraction with organic solvents (e.g., diethyl ether) has long been used to isolate steroids, and is still frequently used. However, with liquid-liquid extraction, steroid recoveries can be low or variable, depending on the sample type and steroids of interest (Appelblad and Irgum, 2002). Liquidliquid extraction can also extract other substances (i.e., other lipids in the brain; Appelblad and Irgum, 2002). These problems can impair accurate measurement of steroids in brain tissue samples. For these reasons, liquid-liquid extraction is being replaced by solid phase extraction over time (Makin and Gower, 2010), or can be paired with solid phase extraction (below; Chao et al., 2011).

Solid phase extraction of brain steroids typically involves loading the sample (in an aqueous buffer) onto a primed and equilibrated sorbent (e.g., silica-bonded $\mathrm{C}_{18}$; Telepchak et al., 2004). We have found $\mathrm{C}_{18}$ columns with $500 \mathrm{mg}$ packing material (e.g., Agilent Bond Elut LRC-C18 OH, \#12113045) mounted on a glass vacuum manifold (UCT \#VMF024GL) to be suitable. After column priming and sample loading are completed, the sample is thoroughly washed to remove interfering substances (Appelblad and Irgum, 2002). With the correct wash(es), interfering substances can be effectively removed, while maintaining high steroid recoveries (Newman et al., 2008a). The selection of an effective wash step is dependent on the analyte, study species, tissue type, and method for steroid quantification (e.g., immunoassay, LC-MS/MS). Work in our laboratory, which has focused on unconjugated steroids, has found that washing with $10 \mathrm{ml}$ deionized water is sufficient for songbird brain samples, but washing with $10 \mathrm{ml} \mathrm{40 \%} \mathrm{methanol} \mathrm{is} \mathrm{required} \mathrm{for} \mathrm{mouse} \mathrm{and} \mathrm{rat} \mathrm{brain}$ samples (Figure 1). This might be related to species differences in brain lipid content. Note that $40 \%$ methanol also elutes conjugated (e.g., sulfated, glucuronidated) steroids (Bélanger et al., 1990; Wang et al., 1997; Liere et al., 2000). More stringent washes (e.g., 40\% methanol, or deionized water followed by hexanes) may also be required if extracted steroids are to be separated by high-performance liquid chromatography (HPLC). After washing, steroids are slowly eluted off the sorbent into borosilicate glass vials or tubes. Elution of unconjugated steroids may be performed with $85-100 \%$ methanol, ethyl acetate, or one followed by the other (Bélanger et al., 1990; Wang et al., 1997; Scott and Ellis, 2007; Wong et al., 2008). Eluting unconjugated steroids with 85-90\% methanol might be useful because $100 \%$ methanol can also elute steroids conjugated to fatty acids (Bélanger et al., 1990; Wang et al., 1997; Liere et al., 2004). It is critical to use the appropriate grade of solvents for solid phase extraction (e.g., HPLC-grade, MS-grade). Finally, solid phase extraction can be automated with robotics 

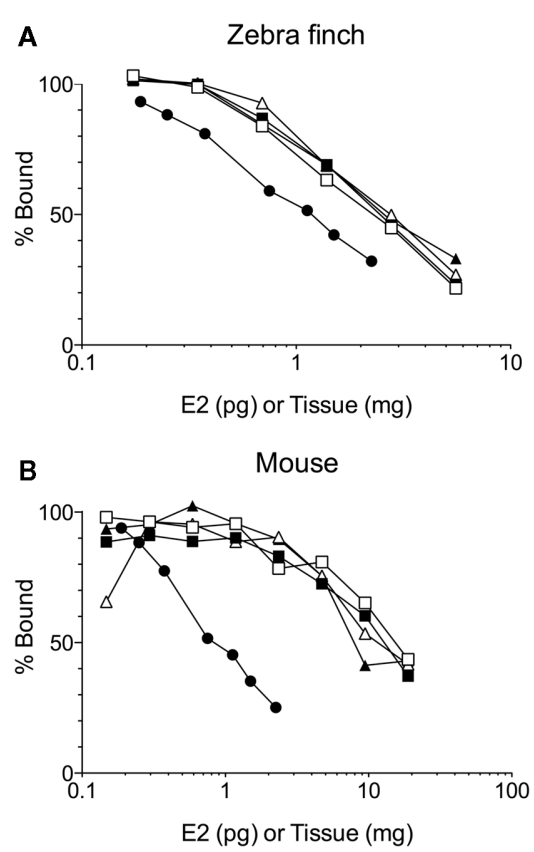

FIGURE 1 | Solid phase extraction of steroids from increasing amounts of brain tissue per assay tube. Samples were loaded onto $\mathrm{C}_{18}$ columns and washed with $10 \mathrm{ml}$ of $0,10,20$, or $40 \%$ methanol $(\mathrm{MeOH})$ in water. Steroids were then eluted from the $\mathrm{C}_{18}$ columns with $5 \mathrm{ml}$ of $90 \% \mathrm{MeOH}$. (A) The different washes have no effect on measurement of $17 \beta$-estradiol $\left(E_{2}\right)$ in zebra finch brain (Taves and Soma, unpublished data). (B) The different washes do affect measurement of $E_{2}$ in mouse brain (Taves and Soma, unpublished data). (C) The different washes also affect measurement of corticosterone in rat brain (adapted with permission from Brummelte et al., 2010). The methods for all validations are similar (see Newman et al., 2008a). Briefly, brain tissue was homogenized in deionized water, and then $\mathrm{MeOH}$ was added. The
C

$$
\begin{aligned}
& \rightarrow \text { Standard curve } \\
& -0 \% \mathrm{MeOH} \\
& -10 \% \mathrm{MeOH} \\
& -20 \% \mathrm{MeOH} \\
& \rightarrow-40 \% \mathrm{MeOH}
\end{aligned}
$$

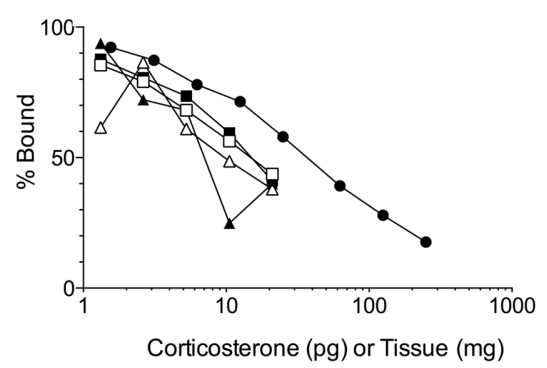

samples were mixed and then left overnight at $4^{\circ} \mathrm{C}$. The samples were mixed again and centrifuged $\left(3000 \mathrm{~g}, 10 \mathrm{~min}, 2^{\circ} \mathrm{C}\right)$. Supernatants $(\leq 1 \mathrm{ml})$ were diluted with $10 \mathrm{ml}$ deionized water and loaded onto $C_{18}$ columns $\left(500 \mathrm{mg} C_{18}\right.$, non-endcapped). Prior to sample loading, the $C_{18}$ columns were primed with $3 \mathrm{ml}$ ethanol and equilibrated with $10 \mathrm{ml}$ deionized water. After sample loading, columns were washed with 0,10,20, or $40 \% \mathrm{MeOH}(10 \mathrm{ml})$ and steroids were eluted with $5 \mathrm{ml} 90 \% \mathrm{MeOH}$. Eluates were dried in a vacuum centrifuge and resuspended in assay buffer. All reagents were HPLC-grade. $E_{2}$ was measured using an ultrasensitive and specific radioimmunoassay (Beckman, DSL-4800; Charlier et al., 2010), and corticosterone was also measured using a radioimmunoassay (MP Biomedicals, cat. 07120103, Washburn et al., 2002).

to increase sample throughput (e.g., Gilson \#GX-274 ASPEC or Hamilton STARlet).

Solid phase extraction gives reliable recovery of very low steroid amounts from small samples. The combination of high steroid recovery and high precision make solid phase extraction an extremely useful tool (Telepchak et al., 2004). It is critical to routinely check the effectiveness of the extraction procedure. Note that some brands of $\mathrm{C}_{18}$ columns can show lot-to-lot variation, and thus it is preferable to extract all the samples from one experiment with columns from the same lot. Furthermore, extraction performance should not be tested solely with radiolabeled steroids because this can overlook some problems. The use of only radiolabeled steroids ignores the potential co-elution of interfering substances (originating from the sample itself or from the $\mathrm{C}_{18}$ column) and damage to the steroid analytes during processing (Scott and Ellis, 2007). Thus, it is important to routinely check extraction performance with unlabeled steroid standards ("quality controls") and water blanks.

After eluates have been collected, they can be dried at 40$60^{\circ} \mathrm{C}$ (Liere et al., 2000). We have found that drying at 50 or $60^{\circ} \mathrm{C}$ reduces drying time without affecting steroid measurement (Table 1; our unpublished results). Drying is typically done under a stream of high-purity nitrogen with a sample concentrator (e.g.,
Techne Dri-Block DB-3) or in a vacuum centrifuge (e.g., Thermo Scientific SPD111V SpeedVac). The dried steroid residue can then be resuspended for quantification, for example via immunoassay. We have found that a small amount of absolute ethanol improves steroid resuspension into an aqueous buffer (Newman et al., 2008a), but care must be taken because ethanol (or impurities therein) can affect some immunoassays (Ocvirk et al., 2009; Charlier et al., 2010). Alternatively, after solid phase extraction, steroids can be separated via chromatography prior to quantification (see below).

\section{CHROMATOGRAPHIC SEPARATION CELITE COLUMN CHROMATOGRAPHY}

The $\mathrm{C}_{18}$ columns used for solid phase extraction are relatively short, and although they can separate conjugated steroids from unconjugated steroids (Liere et al., 2004), they have little ability to separate different unconjugated steroids from each other (e.g., separate testosterone from estradiol). In many cases, it is useful to separate the steroids present in a brain tissue sample prior to steroid measurement. Steroid separation allows several steroids to be measured (e.g., via immunoassays) without splitting the sample, which is useful when the tissue sample is small. Furthermore, with immunoassays, antibody cross-reactivity can be a 
Table 1 | Effect of drying temperature on measured steroid values.

\begin{tabular}{llll}
\hline & $\mathbf{4 0}^{\circ} \mathbf{C}(\%)$ & $\mathbf{5 0}^{\circ} \mathbf{C}(\%)$ & $\mathbf{6 0}^{\circ} \mathbf{C}(\%)$ \\
\hline Cortisol & 100 & 114 & 101 \\
Corticosterone & 100 & 108 & 113 \\
Progesterone & 100 & 96 & 103 \\
\hline
\end{tabular}

Samples were dried in a preheated Thermo Scientific SPD111V SpeedVac. Samples dried at $40^{\circ} \mathrm{C}$ (the most common temperature used across many laboratories) were used as the baseline, and samples dried at 50 and $60^{\circ} \mathrm{C}$ are expressed as a percent of this baseline. Each value is the mean of three samples. Drying at 40,50 , and $60^{\circ} \mathrm{C}$ took approximately 3.0, 2.5, and 2.0 h, respectively. Taves and Soma, unpublished data.

concern (see below), and this concern can be alleviated by steroid separation prior to assay (e.g., Close et al., 2010).

Celite column chromatography uses columns or cartridges containing celite (highly porous, diatomaceous earth). Samples are loaded onto celite columns, and then different steroids are eluted off with different organic solvents. Celite chromatography has sufficient resolving power to separate multiple steroids and has been used in numerous studies of plasma and brain steroids (Wingfield and Farner, 1975; Corpéchot et al., 1981; von Schoultz et al., 1990; Wang et al., 1997; Frye et al., 2000; Dinger and Frye, 2004; Rosario et al., 2004; Pradhan et al., 2010b). Nonetheless, celite columns have less resolving power than HPLC or gas chromatography.

\section{HIGH-PERFORMANCE LIOUID CHROMATOGRAPHY}

High-performance liquid chromatography is often used to separate steroids in a sample. Reversed-phase HPLC using a $\mathrm{C}_{18} \mathrm{HPLC}$ column (e.g., Waters SymmetryShield, $4.6 \mathrm{~mm} \times 250 \mathrm{~mm}, 5 \mu \mathrm{m}$ silica particles) is often used for such purposes, allowing multiple steroids to be collected and measured, without the need to split the sample (Figure 2). Furthermore, for immunoassays, HPLC separation removes potentially cross-reactive steroids, resulting in greater confidence in immunoassay measurements. HPLC often requires minimal sample preparation, as steroids need not be derivatized beforehand. This allows for fraction collection and quantification by immunoassay (Mensah-Nyagan et al., 1996; Munetsuna et al., 2009), more extensive purification and analysis (Mensah-Nyagan et al., 1996; Liere et al., 2000, 2004), or subsequent analysis via tandem mass spectrometry (Liu et al., 2003; Krone et al., 2010).

\section{GAS CHROMATOGRAPHY}

Steroid separation can also be done via gas chromatography, prior to mass spectrometry (Vallée et al., 2000; Alomary et al., 2001). Gas chromatography requires some sample preparation, as steroids are generally derivatized prior to GC/MS analysis. While derivatization can greatly increase sensitivity and aid in determination of steroid structure, it can be a time-consuming process and can convert conjugated steroids into unconjugated steroids (Soldin and Soldin, 2009) or even convert cholesterol into steroids (Schumacher et al., 2008; Liere et al., 2009). Different conjugated steroids (e.g., DHEA-sulfate and DHEA-glucuronide) may also be converted into the same form, resulting in conjugate misidentification (Liu et al., 2003). Additionally, the derivatization process is challenging to automate, which reduces sample throughput (Krone et al., 2010). Nonetheless, GC/MS is well suited for the identification of novel steroidal compounds (Krone et al., 2010). Further, the National Institute of Standards and Technology (NIST) GC/MS database search capability is a powerful tool to aid in the discovery and analysis of novel steroids.

\section{STEROID QUANTIFICATION IMMUNOASSAYS}

Immunoassays include both radioimmunoassays (RIA) and enzyme-linked immunosorbent assays (ELISA, also known as, EIA). Immunoassays are still the most common way to measure steroids, because of their rapidity, simplicity, sensitivity, and cost-effectiveness. Furthermore, many RIA and ELISA kits for steroids are commercially available, contributing to the popularity of immunoassays. Many commercially available RIA kits can be modified to greatly increase their sensitivity. For example, we have modified a double-antibody ${ }^{125}$ I RIA kit to detect sub-picogram amounts of $17 \beta$-estradiol (Charlier et al., 2010). This modified assay is also accurate, specific, and precise. Samples are usually measured in duplicate, requiring the sample to be split in half, but the high precision of this estradiol assay allows samples to be run as singletons, which is useful when the sample is limited (Charlier et al., 2011).

There are some disadvantages associated with the use of immunoassays. One limitation is antibody cross-reactivity, particularly with polyclonal antibodies. Antibodies exhibit widely varying degrees of specificity for their antigen and may bind molecules other than the target of interest, such as closely related steroids (Chard, 1995). Several measures can alleviate concerns about antibody cross-reactivity: selection of a specific antibody, checking closely related steroids for antibody binding, and chromatographic separation of steroids prior to immunoassay.

Another potential problem is that different matrices can affect antibody binding. Most commercially available steroid immunoassay kits are designed to measure steroids in unextracted plasma, serum, or saliva samples, and thus the standards in the standard curve contain the steroid in an appropriate matrix (i.e., similar to serum or saliva). However, when steroids in brain samples are extracted and resuspended in an aqueous buffer that does not contain serum or saliva components (e.g., phosphate-buffered saline with gelatin, PBSG), the antibody can show increased binding to the analyte (possibly due to reduced matrix interference). Thus, extracted steroids resuspended in PBSG should be compared to a standard curve that is also diluted in PBSG. These "matrix effects" can affect steroid measurements, especially at low steroid concentrations.

\section{MASS SPECTROMETRY}

Mass spectrometry, following either gas or liquid chromatography, is highly specific and is currently the "gold standard" for definitive identification of analyte molecules (Alomary et al., 2001; Soldin and Soldin, 2009; Makin and Gower, 2010). Mass spectrometry also allows for simultaneous measurement of many steroids in a single sample, or "steroid profiling" (Liu et al., 2003; Ebner et al., 2006; Meffre et al., 2007; Soldin and Soldin, 2009; Koren et al., submitted). This can now be used to measure both unconjugated steroids and intact steroid sulfates and glucuronides (Jäntti et al., 


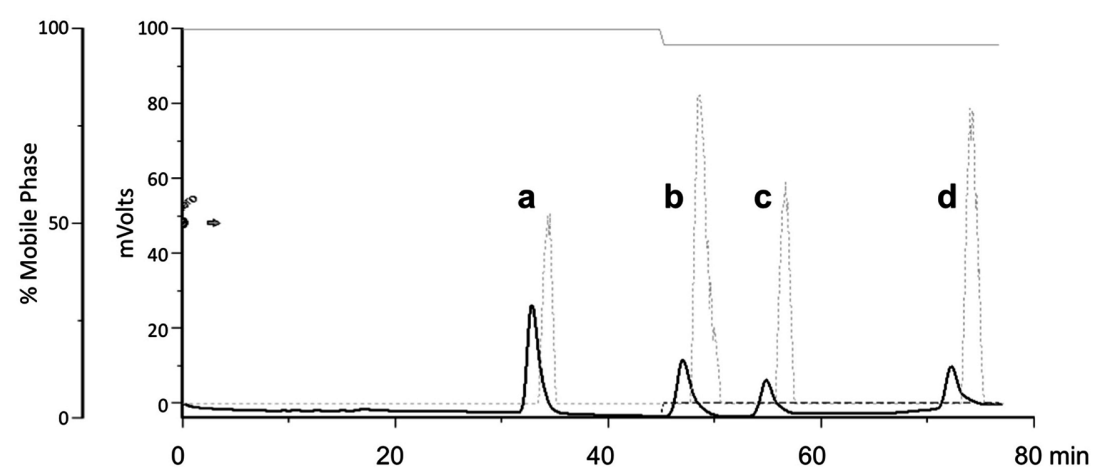

FIGURE 2 | High-performance liquid chromatography separation of (a) cortisol, (b) corticosterone, (c) 11-deoxycortisol, and (d)

11-deoxycorticosterone. To separate these glucocorticoids, we used reversed-phase HPLC (Gilson 322) with a Waters SymmetryShield $\mathrm{C}_{18}$ column (4.6 mm $\times 250 \mathrm{~mm}, 5 \mu \mathrm{m}$ silica particles). The mobile phase consisted of $50 \%$ HPLC-grade methanol in HPLC-grade water with $0.01 \%$ glacial acetic acid (solvent $A$; indicated by the solid gray line at top). At $45 \mathrm{~min}, 5 \%$ isopropanol (solvent $\mathrm{B}$; dashed gray line at the bottom) was added in order to elute the final peaks more rapidly. The solid black line indicates radioinert steroids measured with a UV detector, and the dotted gray line indicates ${ }^{3} \mathrm{H}$-labeled steroids measured with a radioflow detector (as described in Mensah-Nyagan et al., 2008; Pradhan et al., 2008, 2010a). Detection of radiolabeled steroids occurs $1.6 \mathrm{~min}$ later than radioinert steroids because of the extra length of tubing between the UV and radioflow detectors. A fraction collector was then used to collect glucocorticoids for quantification via enzyme immunoassay (EIA) or radioimmunoassay (Taves et al., unpublished results).
2010). These characteristics have contributed to the growing use of mass spectrometry (and tandem mass spectrometry) in steroid analysis (Mensah-Nyagan et al., 1996; Griffiths et al., 2001; Liere et al., 2004, 2009; Matsunaga et al., 2004; Wang et al., 2007; Caruso et al., 2008; Krone et al., 2010).

The sensitivity of mass spectrometry has greatly improved. Steroids are typically derivatized prior to GC/MS to increase measurement sensitivity, but this has some disadvantages (see above). Steroids need not be derivatized prior to LC-MS/MS, although this can be done to increase sensitivity and specificity (Higashi and Shimada, 2004; Higashi et al., 2005; Higashi, 2006; Hojo et al., 2009). Since the sensitivity of LC-MS/MS varies for different steroids, derivatization can be used to aid detection of poorly ionized steroids when they are present in low quantities. A variety of derivatization methods can be used, depending on the analyte(s) of interest (Santa, 2011). The method of ion production can also affect sensitivity (Wang et al., 2007). For some steroids, atmospheric pressure photo-ionization might yield greater sensitivity than atmospheric pressure chemical ionization or electrospray ionization (Robb et al., 2000; Guo et al., 2006). Nonetheless, when the amount of brain tissue is extremely limited (e.g., punch samples or samples from neonatal rats) the limits of quantification of mass spectrometry may not be sufficient (Konkle and McCarthy, 2011).

Thus, mass spectrometry provides definitive steroid identification, simultaneous multi-analyte quantification and good sensitivity. However, high equipment costs and operating costs and the need for specific technical expertise are obstacles to using mass spectrometry for steroid analysis (Makin and Gower, 2010; Stanczyk and Clarke, 2010).

\section{INTERPRETATION}

\section{COMPARING STEROID LEVELS IN THE BRAIN AND CIRCULATION}

Many studies directly compare steroid levels in brain tissue with steroid levels in the general circulation. In subjects that have been adrenalectomized and/or gonadectomized for a long time, the presence of a steroid in the brain, but not in the circulation, is strong evidence for local steroid synthesis (Corpéchot et al., 1981; Concas et al., 2000; Gomez-Sanchez et al., 2005; Croft et al., 2008; Higo et al., 2011). Furthermore, in gonad- and adrenal-intact subjects, if tissue steroid levels are higher than circulating steroid levels, then these data suggest that steroids are locally synthesized, locally sequestered by tissue binding sites, or locally released from steroid binding proteins in the blood. These alternative possibilities can be tested, for example, by measuring steroidogenic enzymes and/or steroid binding sites (Taves et al., 2011). Some representative measurements of endogenous steroid levels in intact adult male rats are given in Table 2 .

When comparing steroid levels in the brain and circulation, a critical point is that the use of plasma samples significantly overestimates steroid concentrations in the blood. Steroid concentrations in plasma are roughly twice as high as steroid concentrations in whole blood (Taves et al., 2010). Thus, for a more representative measurement of actual circulating steroid levels, it is informative to measure steroids in whole blood samples as well as plasma samples (Figure 3).

Another issue is that most studies measure total steroid levels (free + bound) in brain and plasma samples. In the case of corticosterone and cortisol, over $90 \%$ of these glucocorticoids in plasma are bound with high affinity to corticosteroid-binding globulin, and are thus unable to readily enter tissues (Hammond, 1990; Breuner and Orchinik, 2002; Charlier et al., 2009). Since only free (unbound) steroids are available to enter tissues, plasma free steroid levels are also informative for comparison to tissue steroid levels (as in Little et al., 2008; Figure 4).

If local steroid synthesis occurs at low levels or only in specific cells or subcellular compartments (e.g., mitochondria, presynaptic terminals), then the average tissue steroid concentration may be similar to or lower than the circulating steroid concentration (Newman and Soma, 2011). For all of the above reasons, when 
Table 2 | Selected measurements of endogenous steroid levels in adult male rat plasma or serum (ng/ml) and brain tissue (ng/g).

\begin{tabular}{|c|c|c|c|c|c|c|}
\hline Steroid & Plasma/serum & Cortex & Hippocampus & Hypothalamus & Cerebellum & Whole brain \\
\hline Pregnenolone & n.d. -0.9 & $0.4-7.0$ & 4.8 & $11-12$ & $0.4-19$ & $1.7-4.9$ \\
\hline Progesterone & $0.5-2.2$ & $1.5-7.0$ & 4.6 & 0.9 & $0.7-5.3$ & $0.4-0.7$ \\
\hline Testosterone & $1.2-4.2$ & $0.1-2.6$ & 4.9 & 14 & $2.3-2.4$ & $1.4-2.2$ \\
\hline $17 \beta$-Estradiol & n.d. -0.004 & 0.1 & 2.3 & n.a. & 0.02 & n.d. \\
\hline
\end{tabular}

All brain steroid measurements were obtained after solid phase extraction. In some cases, steroid extracts were further purified using high-performance liquid chromatography, gas chromatography, or thin-layer chromatography. Steroids were quantified using radioimmunoassay or mass spectrometry. DHEA, dehydroepiandros-

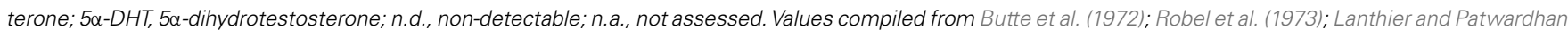
(1987); Purdy et al. (1991); Korneyev et al. (1993b); Wang et al. (1997); Vallée et al. (2000); Ebner et al. (2006); Meffre et al. (2007); Caruso et al. (2008); Hojo et al. (2009); Pesaresi et al. (2010).

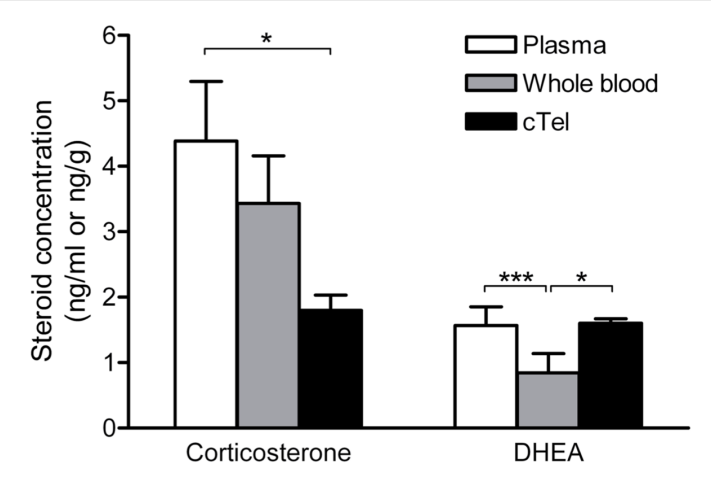

FIGURE 3 | Corticosterone and DHEA levels in zebra finch plasma, whole blood, and brain (cTel, caudal telencephalon). For corticosterone, brain levels are significantly lower than plasma levels but not significantly lower than whole blood levels. For DHEA, brain and plasma levels are similar, but brain levels are significantly higher than whole blood levels. Thus, the use of plasma samples (which overestimate circulating steroid levels) or whole blood samples can lead to very different interpretations when comparing tissue steroid levels against circulating steroid levels. ${ }^{*} p<0.05,{ }^{* *} p<0.001$. Reprinted with permission from Taves et al. (2010).

total steroid levels in brain tissue are similar to or even lower than total steroid levels in plasma, one cannot exclude the possibility of local steroid synthesis on the basis of this observation alone. Other forms of evidence (e.g., steroidogenic enzyme expression) are useful for interpreting such a pattern of results.

To facilitate comparison of brain and circulating steroid levels, it is extremely useful to present brain steroid concentrations and circulating steroid concentrations in comparable units (e.g., ng/g wet weight for brain, $\mathrm{ng} / \mathrm{ml}$ for plasma or whole blood). Note that $1 \mathrm{ml}$ of plasma or blood weighs very close to $1 \mathrm{~g}$ (Schmidt et al., 2008; Taves et al., 2010). Some papers use different units for brain steroid concentrations and plasma steroid concentrations (e.g., $\mathrm{ng} / \mathrm{mg}$ protein for brain, $\mathrm{nM}$ for plasma). This practice complicates the comparison of brain and plasma steroid concentrations.

\section{COMPARING STEROID LEVELS IN DIFFERENT BRAIN REGIONS}

Within an individual brain, a comparison of steroid levels in different regions can identify which regions are most active as steroid producers or targets (von Schoultz et al., 1990; Toran-Allerand et al., 2005; Little et al., 2008; Newman and Soma, 2009; Charlier et al., 2010). This is important in identifying region-specific effects of experimental treatment. For example, if an experimental treatment elevates steroid levels in a specific brain region, but not in other brain regions or circulating blood, this indicates local steroid production (or accumulation) in that specific region (e.g., Little et al., 2008). Comparing steroid levels across brain regions is somewhat more straightforward than comparing steroid levels between brain and blood.

\section{EFFECTS OF PERIPHERAL STEROIDS ON BRAIN STEROID LEVELS}

Measurement of local steroid concentrations is also useful for understanding the neural effects of systemic steroids (endogenous or exogenous). It is generally assumed that increases in systemic steroid levels result in concurrent increases in steroid levels in target tissues, but this is not necessarily the case. For example, in rats, a rise in plasma corticosterone is followed by a rise in brain corticosterone (as measured by microdialysis), but surprisingly only after a 20-min delay (Droste et al., 2008). Systemically administered steroids may also be metabolized before reaching the brain or within the brain itself (Edinger and Frye, 2004), and some steroids are preferentially excluded from the brain via active transport by P-glycoprotein in the blood-brain barrier (Karssen et al., 2001). By measuring steroid levels in target tissues (such as brain), researchers can test whether a systemic steroid treatment results in locally elevated steroid levels, and whether local steroid levels are within the physiological range. Furthermore, as some protein-bound circulating steroids have minimal access to the brain (Pardridge and Mietus, 1979), systemic steroid treatments that result in supraphysiological levels in the blood may produce only moderately elevated steroid levels in the brain (e.g., Amateau et al., 2004). Finally, note that systemically administered steroids can regulate the synthesis of neurosteroids (e.g., Soma et al., 2004).

\section{INADVERTENT INDUCTION OF STEROIDOGENIC ENZYMES IN THE BRAIN}

Injuries to brain tissue can have rapid and enduring effects on steroidogenic enzyme activities around the damaged brain tissue. 


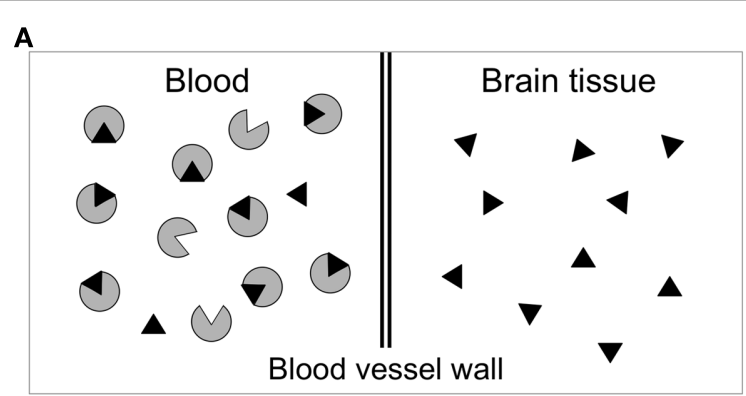

$\mathbf{\Delta}$ = corticosterone, $\curvearrowleft=$ corticosteroid-binding globulin

B

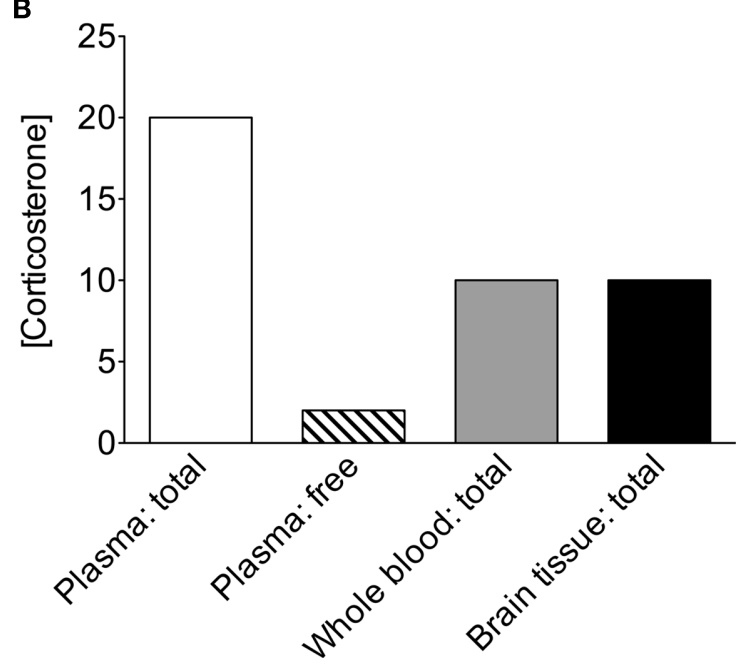

FIGURE 4 | Theoretical comparison of circulating and tissue steroid concentrations. (A) If the same amounts of steroid are present in equal volumes of blood and brain, different interpretations can be made, depending on how steroids are quantified in blood. In the circulation, the vast majority of corticosterone is bound to corticosteroid-binding globulin (CBG; Hammond, 1990). CBG-bound steroids have very limited access to tissue and limited ability to cross the blood-brain barrier. (B) Corticosterone concentrations in whole blood are approximately $50 \%$ of those in plasma (Taves et al., 2010), and within plasma, the vast majority of corticosterone is bound to CBG. In the above theoretical scenario, if whole blood

corticosterone is measured, then circulating levels appear identical to tissue levels. If plasma total corticosterone is measured, then circulating levels appear much higher than tissue levels. If plasma free corticosterone is measured, then circulating levels appear much lower than tissue levels. Thus, the use of whole blood steroid measurements or plasma free steroid measurements is highly informative in addition to plasma total steroid measurements.

For example, aromatase is expressed constitutively in avian and mammalian neurons (Balthazart et al., 1993; Naftolin et al., 1996; Saldanha et al., 2000), but neuropil perturbation, such as by excitotoxicity (Azcoitia et al., 2001), penetrating injury (GarciaSegura et al., 1999; Peterson et al., 2001), or anoxia/ischemia (Garcia-Segura et al., 2001), induces additional aromatase expression in astroglia around the site of primary damage (Saldanha et al., 2010). This induction of aromatase occurs in hours and lasts weeks (Wynne et al., 2008) or months post-injury (GarciaSegura et al., 2001). Importantly, this induction occurs in a cell type that only expresses aromatase in vitro or following damage to the brain (Schlinger et al., 1994; Zwain and Yen, 1999; Saldanha et al., 2009). Thus, when experimental techniques that cause physical damage of neural tissue are used, measured steroid levels likely reflect a combination of constitutive and induced estrogen levels. Such techniques could include brain slicing or dissociation prior to tissue culture, microdialysis probe or cannula insertion, saline perfusion, or a delay between euthanasia and brain freezing. Increases in brain estradiol levels occur within minutes of insult (Saleh et al., 2004; Taves et al., 2010). Other steroids might also be altered during routine tissue collection procedures.

\section{CONCLUSION AND FUTURE DIRECTIONS}

Numerous studies have measured steroids in plasma or serum, and many studies have examined steroidogenic enzyme expression in the brain. However, far fewer studies have measured steroids in the brain. For example, many more studies have measured aromatase than estradiol levels in the brain. However, measurement of tissue steroid concentrations is critical to understanding the numerous roles and regulation of steroid signaling molecules in the brain. Such measurements involve tissue collection, steroid extraction, and steroid separation and quantification. At each of these steps, there are various methodological approaches that may be used, and the selection of a particular approach necessitates weighing the costs and benefits of each, with respect to the goals of the particular experiment. If the results obtained with different approaches converge to give the same conclusion, then this is strong evidence for a given phenomenon. Thus, the use of various methods within a laboratory or across different laboratories can be useful.

Improvements in steroid extraction and detection are steadily increasing our ability to measure extremely small quantities of steroids $(<0.5 \mathrm{pg}$ of steroid in a sample). Improved measurement sensitivity allows for techniques that measure steroids in samples that are of minimal size (e.g., brain punch samples, smaller microdialysate samples, CSF samples from human infants, tumor biopsies), which can improve the spatial and temporal resolution of brain steroid measurements. Laser capture microdissection gives excellent spatial specificity (de Kloet, 2006), and improved assay sensitivity might permit use of this technique for steroid quantification in brain tissue. Similarly, in vivo microdialysis provides temporal information about brain steroid changes, and improved assay sensitivity will permit the use of shorter dialysate collection windows, providing greater temporal resolution.

In the future, other methods of measuring steroids in the brain could be useful. For example, immunohistochemistry might allow for even greater spatial information about steroids in the brain, particularly at synapses. A few studies have quantified steroids via immunohistochemistry using specific antibodies in fixed neural and non-neural tissues (Dornhorst and Gann, 1978; Saalmann et al., 2007; Tokuda et al., 2011). It is critical that the necessary controls be run (e.g., pre-absorption controls, tissues lacking the steroid of interest) to convincingly demonstrate the specificity of antibody binding in sample tissues.

In addition to quantifying well-known steroids, future studies will undoubtedly discover novel steroids, steroid conjugates, 
and steroid metabolites. GC/MS is especially suited for such exploratory analyses (Krone et al., 2010). The need for identification of novel steroids and steroid metabolites is well illustrated by the case of brain estradiol, whose downstream metabolism remains unclear (Cornil, 2009; Charlier et al., 2011). Note that local steroid metabolism is likely to affect local steroid levels (Jäntti et al., 2010; Charlier et al., 2011). Such studies, along with improvements in steroid profiling and measurement sensitivity, promise to provide a much more detailed understanding of regional and cellular differences in steroid synthesis, action, and metabolism in the brain.

\section{REFERENCES}

Alomary, A. A., Fitzgerald, R. I., and Purdy, R. H. (2001). Neurosteroid analysis. Int. Rev. Neurobiol. 46, 97-115.

Amateau, S. K., Alt, J. J., Stamps, C. L., and McCarthy, M. M. (2004). Brain estradiol content in newborn rats: sex differences, regional heterogeneity, and possible de novo synthesis by the female telencephalon. Endocrinology 145, 2906-2917.

American Veterinary Medical Association. (2007). AVMA Guidelines on Euthanasia. Available at: http://www.avma.org/issues/animal_ welfare/euthanasia.pdf

Appelblad, P., and Irgum, K. (2002). Separation and detection of neuroactive steroids from biological matrices. J. Chromatogr. A 955, 151-182.

Azcoitia, I., Sierra, A., Veiga, S., Honda, S.-I., Harada, N., and Garcia-Segura, L. M. (2001). Brain aromatase is neuroprotective. J. Neurobiol. 47, 318-329.

Balthazart, J., Baillien, M., and Foidart, A. (1993). Brain aromatase and the control of male sexual behavior. J. Steroid Biochem. Mol. Biol. 44, 521-540.

Balthazart, J., and Ball, G. F. (2006). Is brain estradiol a hormone or a neurotransmitter? Trends Neurosci. 29, 241-249.

Barbaccia, M. L., Roscetti, G., Trabucchi, M., Mostallino, M. C., Concas, A., Purdy, R. H., and Biggio, G. (1996). Time-dependent changes in rat brain neuroactive steroid concentrations and GABAA receptor function after acute stress. Neuroendocrinology 63, 166-172.

Baulieu, E. E. (1998). Neurosteroids: a novel function of the brain. Psychoneuroendocrinology 23, 963-987.

Bélanger, A., Couture, J., Caron, S., and Roy, R. (1990). Determination of nonconjugated and conjugated steroid levels in plasma and prostate after separation on C-18 columns. Ann. N. Y. Acad. Sci. 595, 251-259.
Breuner, C. W., and Orchinik, M. (2002). Plasma binding proteins as mediators of corticosteroid action in vertebrates. J. Endocrinol. 175, 99-112.

Brummelte, S., Schmidt, K. L., Taves, M. D., Soma, K. K., and Galea, L. A. M. (2010). Elevated corticosterone levels in stomach milk, serum, and brain of male and female offspring after maternal corticosterone treatment in the rat. Dev. Neurobiol. 70, 714-725.

Bruzzone, F., Do Rego, J.-L., Luu-The, V., Pelletier, G., Vallarino, M., and Vaudry, H. (2010). Immunohistochemical localization and biological activity of $3 \beta$-hydroxysteroid dehydrogenase and $5 \alpha$-reductase in the brain of the frog, Rana esculenta, during development. J. Chem. Neuroanat. 39, 35-50.

Butte, J. C., Kakihana, R., and Noble, E. P. (1972). Rat and mouse brain corticosterone. Endocrinology 90, 1091-1100.

Callard, G. V., Petro, Z., and Ryan, K. J. (1978). Phylogenetic distribution of aromatase and other androgenconverting enzymes in the central nervous system. Endocrinology 103, 2283-2291.

Caruso, D., Scurati, S., Maschi, O., De Angelis, L., Roglio, I., Giatti, S., Garcia-Segura, L. M., and Melcangi, R. C. (2008). Evaluation of neuroactive steroid levels by liquid chromatography-tandem mass spectrometry in central and peripheral nervous system: effect of diabetes. Neurochem. Int. 52, 560-568.

Chao, A., Schlinger, B. A., and RemageHealey, L. (2011). Combined liquid and solid-phase extraction improves quantification of brain estrogen content. Front. Neuroanat. 5:57. doi: 10.3389/fnana.2011.00057

Chard, T. (1995). An Introduction to Radioimmunoassay and Related Techniques, 5th Edn. Amsterdam: Elsevier.

Charlier, T. D., Newman, A. E. M., Heimovics, S. A., Po, K. W. L.,

\section{ACKNOWLEDGMENTS}

We thank Drs. T. D. Charlier, H. B. Fokidis, H. H. Adomat, and K. L. Schmidt for comments on the manuscript and Drs. C. R. Overk, S. E. Perez, and E. J. Mufson for providing mouse brain samples. We also thank L. Bond, E. Ng, and Drs. L. Koren and K. E. Wynne-Edwards for useful discussions. This work was supported by grants from the Canadian Institutes of Health Research (CIHR) and Michael Smith Foundation for Health Research (MSFHR) to Kiran K. Soma, and from NIH (R01NS042767) to Colin J. Saldanha. Matthew D. Taves is a CIHR Canada Graduate Scholar and Sarah A. Heimovics is a CIHR and MSFHR Postdoctoral Fellow.

Saldanha, C. J., and Soma, K. K. (2011). Rapid effects of aggressive interactions on aromatase activity and oestradiol in discrete brain regions of wild male white-crowned sparrows. J. Neuroendocrinol. 23, 742-753.

Charlier, T. D., Po, K. W. L., Newman, A. E. M., Shah, A. H., Saldanha, C. J., and Soma, K. K. (2010). 17 $\beta$-Estradiol levels in male zebra finch brain: combining Palkovits punch and an ultrasensitive radioimmunoassay. Gen. Comp. Endocrinol. 167, 18-26.

Charlier, T. D., Underhill, C., Hammond, G. L., and Soma, K. K. (2009). Effects of aggressive encounters on plasma corticosteroid-binding globulin and its ligands in whitecrowned sparrows. Horm. Behav. 56, 339-347.

Chin, E. H., Shah, A. H., Schmidt, K. L., Sheldon, L. D., Love, O. P., and Soma, K. K. (2008). Sex differences in DHEA and estradiol during development in a wild songbird: jugular versus brachial plasma. Horm. Behav. 54, 194-202.

Close, D. A., Yun, S.-S., McCormick, S. D., Wildbill, A. J., and Li, W. (2010). 11-Deoxycortisol is a corticosteroid hormone in the lamprey. Proc. Natl. Acad. Sci. U.S.A. 107, 13942-13947.

Compagnone, N. A., and Mellon, S. H. (2000). Neurosteroids: biosynthesis and function of these novel neuromodulators. Front. Neuroendocrinol. 21:1-56. doi: 10.1006/frne.1999.0188

Concas, A., Porcu, P., Sogliano, C., Serra, M., Purdy, R. H., and Biggio, G. (2000). Caffeine-induced increases in the brain and plasma concentrations of neuroactive steroids in the rat. Pharmacol. Biochem. Behav. 66, 39-45.

Cornil, C. A. (2009). Rapid regulation of brain oestrogen synthesis: the behavioural roles of oestrogens and their fates. J. Neuroendocrinol. 21, 217-226.
Corpéchot, C., Robel, P., Axelson, M. Sjövall, J., and Baulieu, E.-E. (1981). Characterization and measurement of dehydroepiandrosterone sulfate in rat brain. Proc. Natl. Acad. Sci. U.S.A. 78, 4704-4707.

Croft, A. P., O'Callaghan, M. J., Shaw, S. G., Connolly, G., Jacquot, C., and Little, H. J. (2008). Effects of minor laboratory procedures, adrenalectomy, social defeat or acute alcohol on regional brain concentrations of corticosterone. Brain Res. 1238, 12-22.

de Kloet, E. R. (2006). From punch to profile. Neurochem. Res. 31, 131-135.

Diotel, N., Do Rego, J.-L., Anglade, I., Vaillant, C., Pellegrini, E., Gueguen, M.-M., Mironov, S., Vaudry, H., and Kah, O. (2011). Activity and expression of steroidogenic enzymes in the brain of adult zebrafish. Eur. J. Neurosci. 34, 45-56.

Diotel, N., Le Page, Y., Mouriec, K., Tong, S.-K., Pellegrini, E., Vaillant, C., Anglade, I., Brion, F., Pakdel, F., Chung, B.-C., and Kah, O. (2010). Aromatase in the brain of teleost fish: expression, regulation and putative functions. Front Neuroendocrinol. 31:172-192. doi: 10.1016/j.yfrne.2010.01.003

Do Rego, J. L., Seong, J. Y., Burel, D., Leprince, J., Luu-The, V., Tsutsui, K., Tonon, M.-C., Pelletier, G., and Vaudry, H. (2009). Neurosteroid biosynthesis: enzymatic pathways and neuroendocrine regulation by neurotransmitters and neuropeptides. Front. Neuroendocrinol. 30:259-301. doi: 10.1016/j.yfrne.2009.05.006

Dornhorst, A., and Gann, D. S. (1978). Immunoperoxidase stains cortisol in adrenal and pituitary. J. Histochem. Cytochem. 26, 909-913.

Droste, S. K., de Groote, L., Atkinson, H. C., Lightman, S. L., Reul, J. M. H. M., and Linthorst, A. C. E. (2008). Corticosterone levels in the brain show a distinct ultradian rhythm but a delayed response to forced swim test. Endocrinology 149, 3244-3253. 
Ebner, M. J., Corol, D. I., Havlíková, H., Honour, J. W., and Fry, J. P. (2006). Identification of neuroactive steroids and their precursors and metabolites in adult male rat brain. Endocrinology 147, 179-190.

Edinger, K. L., and Frye, C. A. (2004). Testosterone's analgesic, anxiolytic, and cognitive-enhancing effects may be due in part to actions of its $5 \alpha$-reduced metabolites in the hippocampus. Behav. Neurosci. 118, 1352-1364.

Forlano, P. M., Deitcher, D. L., Myers, D. A., and Bass, A. H. (2001). Anatomical distribution and cellular basis for high levels of aromatase activity in the brain of teleost fish: aromatase enzyme and mRNA expression identify glia as source. J. Neurosci. 21, 8943-8955.

Frye, C. A., Petralia, S. M., and Rhodes, M. E. (2000). Estrous cycle and sex differences in performance on anxiety tasks coincide with increases in hippocampal progesterone and 3 $\alpha, 5 \alpha$-THP. Pharmacol. Biochem. Behav. 67, 587-596.

Garcia-Segura, L. M., Azcoitia, I., and DonCarlos, L. L. (2001). Neuroprotection by estradiol. Prog. Neurobiol. 63, 29-60.

Garcia-Segura, L. M., Wozniak, A., Azcoitia, I., Rodriguez, J. R., Hutchison, R. E., and Hutchison, J. B. (1999). Aromatase expression by astrocytes after brain injury: implications for local estrogen formation in brain repair. Neuroscience 89 , 567-578.

Gomez-Sanchez, C. E., Zhou, M. Y., Cozza, E. N., Morita, H., Foecking, M. F., and Gomez-Sanchez, E. P. (1997). Aldosterone biosynthesis in the rat brain. Endocrinology 138, 3369-3373.

Gomez-Sanchez, E. P., Ahmad, N., Romero, D. G., and Gomez-Sanchez, C. E. (2005). Is aldosterone synthesized within the rat brain? Am. J. Physiol. Endocrinol. Metab. 288, E342-E346.

González-Gil, A., Silván, G., GarcíaPartida, P., and Illera, J. C. (2006). Serum glucocorticoid concentrations after halothane and isoflurane anaesthesia in New Zealand white rabbits. Vet. Rec. 159, 51-52.

Goodson, J. L., Saldanha, C. J., Hahn, T. P., and Soma, K. K. (2005). Recent advances in behavioral neuroendocrinology: insights from studies on birds. Horm. Behav. 48, 461-473.

Griffiths, W. J., Jonsson, A. P., Liu, S., Rai, D. K., and Wang, Y. (2001). Electrospray and tandem mass spectrometry in biochemistry. Biochem. J. 355, 545-561.
Guazzo, E. P., Kirkpatrick, P. J., Goodyer, I. M., Shiers, H. M., and Herbert, J. (1996). Cortisol, dehydroepiandrosterone (DHEA), and DHEA sulfate in the cerebrospinal fluid of man: relation to blood levels and the effects of age. J. Clin. Endocrinol. Metab. 81, 3951-3960.

Guo, T., Taylor, R. L., Singh, R. J., and Soldin, S. J. (2006). Simultaneous determination of 12 steroids by isotope dilution liquid chromatography-photospray ionization tandem mass spectrometry. Clin. Chim. Acta 372, 76-82.

Hackbarth, H., Küppers, N., and Bohnet, W. (2000). Euthanasia of rats with carbon dioxide - animal welfare aspects. Lab. Anim. 34, 91-96.

Hammond, G. L. (1990). Molecular properties of corticosteroid binding globulin and the sex-steroid binding proteins. Endocr. Rev. 11, 65-79.

Higashi, T. (2006). Trace determination of steroids causing age-related diseases using LC/MS combined with detection-oriented derivatization. Chem. Pharm. Bull. (Tokyo) 54, 1479-1485.

Higashi, T., and Shimada, K. (2004). Derivatization of neutral steroids to enhance their detection characteristics in liquid chromatography-mass spectrometry. Anal. Bioanal. Chem. 378, 875-882.

Higashi, T., Takido, N., and Shimada, K. (2005). Studies on neurosteroids XVII. Analysis of stressinduced changes in neurosteroid levels in rat brains using liquid chromatography-electron capture atmospheric pressure chemical ionization-mass spectrometry. Steroids 70, 1-11.

Higo, S., Hojo, Y., Ishii, Y., Komatsuzaki, Y., Ooishi, Y., Murakami, G., Mukai, H., Yamazaki, T., Nakahara, D., Barron, A., Kimoto, T., and Kawato, S. (2011). Endogenous synthesis of corticosteroids in the hippocampus. PLoS ONE 6, e21631. doi: 10.1371/journal.pone.0021631

Hojo, Y., Hattori, T., Enami, T., Furukawa, A., Suzuki, K., Ishii, H., Mukai, H., Morrison, J. H., Janssen, W. G. M., Kominami, S., Harada, N., Kimoto, T., and Kawato, S. (2004). Adult male rat hippocampus synthesizes estradiol from pregnenolone by cytochromes P45017 $\alpha$ and P450 aromatase localized in neurons. Proc. Natl. Acad. Sci. U.S.A. 101, 865-870. Hojo, Y., Higo, S., Ishii, H., Ooishi, Y., Mukai, H., Murakami, G., Kominami, T., Kimoto, T., Honma, S., Poirier, D., and Kawato, S. (2009). Comparison between hippocampus-synthesized and circulation-derived sex steroids in the hippocampus. Endocrinology 150, 5106-5112.

Holloway, C. C., and Clayton, D. F. (2001). Estrogen synthesis in the male brain triggers development of the avian song control pathway in vitro. Nat. Neurosci. 4, 170-175.

Holson, R. R. (1992). Euthanasia by decapitation: evidence that this technique produces prompt, painless unconsciousness in laboratory rodents. Neurotoxicol. Teratol. 14, 253-257.

Jäntti, S. E., Tammimäki, A., Raattamaa, H., Piepponen, P., Kostiainen, R., and Ketola, R. A. (2010). Determination of steroids and their intact glucuronide conjugates in mouse brain by capillary liquid chromatographytandem mass spectrometry. Anal. Chem. 82, 3168-3175.

Karmarkar, S. W., Bottum, K. M., and Tischkau, S. A. (2010). Considerations for the use of anesthetics in neurotoxicity studies. Comp. Med. 60, 256-262.

Karssen, A. M., Meijer, O. C., van der Sandt, I. C. J., Lucassen, P. J., de Lange, E. C. M., de Boer, A. G., and de Kloet, E. R. (2001). Multidrug resistance P-glycoprotein hampers the access of cortisol but not corticosterone to mouse and human brain. Endocrinology 142, 2686-2694.

Kim, S.-B., Hill, M., Kwak, Y.-T., Hampl, R., Jo, D.-H., and Morfin, R. (2003). Neurosteroids: cerebrospinal fluid levels for Alzheimer's disease and vascular dementia diagnostics. J. Clin. Endocrinol. Metab. 88, 5199-5206.

Konkle, A. T. M., and McCarthy, M. M. (2011). Developmental time course of estradiol, testosterone, and dihydrotestosterone levels in discrete regions of male and female rat brain. Endocrinology 152, 223-235.

Korneyev, A. Y., Costa, E., and Guidotti, A. (1993a). During anestheticinduced activation of the hypothalamic pituitary adrenal axis, bloodborne steroids fail to contribute to the anesthetic effect. Neuroendocrinology 57, 559-565.

Korneyev, A., Pan, B. S., Polo, A., Romeo, E., Guidotti, A., and Costa, E. (1993b). Stimulation of brain pregnenolone synthesis by mitochondrial diazepam binding inhibitor receptor ligands in vivo. $\mathrm{J}$. Neurochem. 61, 1515-1524.

Kretz, O., Fester, L., Wehrenberg, U., Zhou, L., Brauckmann, S., Zhao, S. Prange-Kiel, J., Naumann, T., Jarry, H., Frotscher, M., and Rune, G. M. (2004). Hippocampal synapses depend on hippocampal estrogen synthesis. J. Neurosci. 24, 5913-5921.
Krone, N., Hughes, B. A., Lavery, G. G., Steward, P. M., Arlt, W., and Shackleton, C. H. L. (2010). Gas chromatography/mass spectrometry (GC/MS) remains a pre-eminent discovery tool in clinical steroid investigations even in the era of fast liquid chromatography tandem mass spectrometry (LC/MS/MS). $J$. Steroid Biochem. Mol. Biol. 121, 496-504.

Lanthier, A., and Patwardhan, V. V. (1987). Effect of heterosexual olfactory and visual stimulation on 5en-3 $\beta$-hydroxysteroids and progesterone in the male rat brain. J. Steroid Biochem. 28, 697-701.

Le Goascogne, C., Robel, P., Gouézou, M., Sananès, N., Baulieu, E.-E., and Waterman, M. (1987). Neurosteroids: cytochrome P$450 \mathrm{scc}$ in rat brain. Science 237, 1212-1215.

Liere, P., Akwa, Y., Weill-Engerer, S., Eychenne, B., Pianos, A., Robel, P., Sjövall, J., Schumacher, M., and Baulieu, E.-E. (2000). Validation of an analytical procedure to measure trace amounts of neurosteroids in brain tissue by gas chromatographymass spectrometry. J. Chromatogr. $B$ 739, 301-312.

Liere, P., Pianos, A., Eychenne, B., Cambourg, A., Bodin, K., Griffiths, W. Schumacher, M., Baulieu, E.-E., and Sjövall, J. (2009). Analysis of pregnenolone and dehydroepiandrosterone in rodent brain: cholesterol autoxidation is the key. J. Lipid. Res. 50, 2430-2444.

Liere, P., Pianos, A., Eychenne, B., Cambourg, A., Liu, S., Griffiths, W., Schumacher, M., Sjövall, J., and Baulieu, E.-E. (2004). Novel lipoidal derivatives of pregnenolone and dehydroepiandrosterone and absence of their sulfated counterparts in rodent brain. J. Lipid Res. 45, 2287-2302.

Little, H. J., Croft, A. P., O'Callaghan, M. J. O., Brooks, S. P., Wang, G., and Shaw, S. G. (2008). Selective increases in regional brain glucocorticoid: a novel effect of chronic alcohol. Neuroscience 156, 1017-1027.

Liu, S., Sjövall, J., and Griffiths, W. J. (2003). Neurosteroids in rat brain: extraction, isolation, and analysis by nanoscale liquid chromatographyelectrospray mass spectrometry. Anal. Chem. 75, 5835-5846.

London, S. E., Monks, D. A., Wade, J., and Schlinger, B. A. (2006). Widespread capacity for steroid synthesis in the avian brain and song system. Endocrinology 147, 5975-5987.

MacLusky, N. J. (2009). Euthanasia in endocrinology: The choices get more complex. Endocrinology 150, 2505-2506. 
Magariños, A. M., Ferrini, M., and De Nicola, A. F. (1989). Corticosteroid receptors and glucocorticoid content in microdissected brain regions: correlative aspects. Neuroendocrinology 50, 673-678.

Makin, H. L. J., and Gower, D. B(2010). Steroid Analysis, 2nd Edn. Dordrecht: Springer.

Matsunaga, M., Ukena, K., Baulieu, E.-E., and Tsutsui, K. (2004). $7 \alpha-$ Hydroxypregnenolone acts as a neuronal activator to stimulate locomotor activity of breeding newts by means of the dopaminergic system. Proc. Natl. Acad. Sci. U.S.A. 101, 17282-17287.

Meffre, D., Pianos, A., Liere, P., Eychenne, B., Cambourg, A., Schumacher, M., Stein, D. G., and Guennoun, R. (2007). Steroid profiling in brain and plasma of male and pseudopregnant female rats after traumatic brain injury: analysis by gas chromatography/mass spectrometry. Endocrinology 148, 2505-2517.

Mellon, S. H., and Griffin, L. D. (2002). Neurosteroids: biochemistry and clinical significance. Trends Endocrinol. Metab. 13, 35-43.

Mensah-Nyagan, A. G., Feuilloley, M., Do-Rego, J. L., Marcual, A., Lange, C., Tonon, M. C., Pelletier, G., and Vaudry, H. (1996). Localization of $17 \beta$-hydroxysteroid dehydrogenase and characterization of testosterone in the brain of the male frog. Proc. Natl. Acad. Sci. U.S.A. 93, 1423-1428.

Mensah-Nyagan, A. G., Saredi, S., Schaeffer, V., Kibaly, C., Meyer, L., Melcangi, R. C., and Patte-Mensah, C. (2008). Assessment of neuroactive steroid formation in diabetic rat spinal cord using high-performance liquid chromatography and continuous flow scintillation detection. Neurochem. Int. 52, 554-559.

Munetsuna, E., Hojo, Y., Hattori, M., Ishii, H., Kawato, S., Ishida, A., Kominami, S. A. J., and Yamazaki, T. (2009). Retinoic acid stimulates $17 \beta$ estradiol and testosterone synthesis in rat hippocampal slice cultures. Endocrinology 150, 4260-4269.

Murphy, E. J. (2010). Brain fixation for analysis of brain lipid-mediators of signal transduction and brain eicosanoids requires head-focused microwave irradiation: an historical perspective. Prostaglandins Other Lipid Mediat. 91, 63-67.

Naftolin, F., Horvath, T. L., Jakab, R. L., Leranth, C., Harada, N., and Balthazart, J. (1996). Aromatase immunoreactivity in axon terminals of the vertebrate brain. Neuroendocrinology 63, 149-155.
Newman, A. E. M., Chin, E. H., Schmidt, K. L., Bond, L., Wynne-Edwards, K. E., and Soma, K. K. (2008a). Analysis of steroids in songbird plasma and brain by coupling solid phase extraction to radioimmunoassay. Gen. Comp. Endocrinol. 155, 503-510.

Newman, A. E. M., Pradhan, D. S., and Soma, K. K. (2008b). Dehydroepiandrosterone and corticosterone are regulated by season and acute stress in a wild songbird: jugular versus brachial plasma. Endocrinology 149, 2537-2545.

Newman, A. E. M., and Soma, K. K. (2009). Corticosterone and dehydroepiandrosterone in songbird plasma and brain: effects of season and acute stress. Eur. J. Neurosci. 29, 1905-1914.

Newman, A. E. M., and Soma, K. K. (2011). Aggressive interactions differentially modulate local and systemic levels of corticosterone and DHEA in a wild songbird. Horm. Behav. 60, 389-396.

O'Callaghan, J. P., and Sriram, K. (2004). Focused microwave irradiation of the brain preserves in vivo protein phosphorylation: comparison with other methods of sacrifice and analysis of multiple phosphoproteins. J. Neurosci. Methods 135, 159-168.

Ocvirk, R., Bisson, J. M., and Murphy, B. E. P. (2009). Alcohols which have been in contact with any plastics may interfere in radioimmunoassays of progesterone. J. Steroid Biochem. Mol. Biol. 113, 150-154.

Palkovits, M. (1973). Isolated removal of hypothalamic or other brain nuclei of the rat. Brain Res. 59, 449-450.

Pardridge, W. M., and Mietus, L. J. (1979). Transport of steroid hormones through the rat blood-brain barrier. J. Clin. Invest. 64, 145-154.

Pesaresi, M., Maschi, O., Giatti, S., Garcia-Segura, L. M., Caruso, D., and Melcangi, R. C. (2010). Sex differences in neuroactive steroid levels in the nervous system of diabetic and non-diabetic rats. Horm. Behav. 57, 46-55.

Peterson, R. S., Saldanha, C. J., and Schlinger, B. A. (2001). Rapid upregulation of aromatase mRNA and protein following neural injury in the zebra finch (Taeniopygia guttata). J. Neuroendocrinol. 13, 317-323.

Pradhan, D. S., Lau, L. Y., Schmidt, K. L., and Soma, K. K. (2010a). 3 $\beta$ HSD in songbird brain: subcellular localization and rapid regulation by estradiol. J. Neurochem. 115, 667-675.

Pradhan, D. S., Newman, A. E. M., Wacker, D. W., Wingfield, J. C.,
Schlinger, B. A., and Soma, K. K. (2010b). Aggressive interactions rapidly increase androgen synthesis in the brain during the non-breeding season. Horm. Behav. 57, 381-389.

Pradhan, D. S., Yu, Y., and Soma, K. K. (2008). Rapid estrogen regulation of DHEA metabolism in the male and female songbird brain. J. Neurochem. 104, 244-253.

Purdy, R. H., Morrow, A. L., Moore, P. H., and Paul, S. M. (1991). Stress-induced elevations of $\gamma$ aminobutyric acid type A receptoractive steroids in the rat brain. Proc. Natl. Acad. Sci. U.S.A. 88, 4553-4557.

Rash, J. M., Jerkunica, I., and Sgoutas, D. S. (1980). Lipid interference in steroid radioimmunoassay. Clin. Chem. 26, 84-88.

Reburn, C. J., and Wynne-Edwards, K. E. (2000). Cortisol and prolactin concentrations during repeated blood sample collection from freely moving, mouse-sized mammals (Phodopus spp.). Comp. Med. 50, 184-198.

Remage-Healey, L., Maidment, N. T., and Schlinger, B. A. (2008). Forebrain steroid levels fluctuate rapidly during social interactions. $\mathrm{Nat}$. Neurosci. 11, 1327-1334.

Rijn, C. M. v., Krijnen, H., MentingHermeling, S., and Coenen, A. M. L. (2011). Decapitation in rats: latency to unconsciousness and the "wave of death.” PLoS ONE 6, e16514. doi: 10.1371/journal.pone.0016514

Robb, D. B., Covey, T. R., and Bruins, A. P. (2000). Atmospheric pressure photoionization: an ionization method for liquid chromatographymass spectrometry. Anal. Chem. 72, 3653-3659.

Robel, P., Corpéchot, C., and Baulieu, E.-E. (1973). Testosterone and androstanolone in rat plasma and tissues. FEBS Lett. 33, 218-220.

Rosario, E. R., Chang, L., Stanczyk, F. Z., and Pike, C. J. (2004). Age-related testosterone depletion and the development of Alzheimer disease. JAMA 292, 1431-1432.

Saalmann, Y. B., Kirkcaldie, M. T. K., Waldron, S., and Calford, M. B. (2007). Cellular distribution of the GABAA receptor-modulating $3 \alpha$-hydroxy, $5 \alpha$-reduced pregnane steroids in the adult rat brain. $J$. Neuroendocrinol. 19, 272-284.

Sakamoto, H., Ukena, K., and Tsutsui, K. (2001a). Activity and localization of $3 \beta$-hydroxysteroid dehydrogenase/ $\Delta 5$ - $\Delta 4$-isomerase in the zebrafish central nervous system. J. Comp. Neurol. 439, 291-305.

Sakamoto, H., Ukena, K., and Tsutsui, K. (2001b). Effects of progesterone synthesized de novo in the developing
Purkinje cell on its dendritic growth and synaptogenesis. J. Neurosci. 21, 6221-6232.

Saldanha, C. J., Duncan, K. A., and Walters, B. J. (2009). Neuroprotective actions of brain aromatase. Front. Neuroendocrinol. 30:106-118. doi: 10.1016/j.yfrne.2009.04.016

Saldanha, C. J., Remage-Healey, L., and Schlinger, B. A. (2011). Synaptocrine signaling: steroid synthesis and action at the synapse. Endocr. Rev. 32, 532-549.

Saldanha, C. J., and Schlinger, B. A. (1997). Estrogen synthesis and secretion in the brownheaded cowbird (Molothrus ater). Gen. Comp. Endocrinol. 105, 390-401.

Saldanha, C. J., Tuerk, M. J., Kim, Y.H., Fernandes, A. O., Arnold, A. P., and Schlinger, B. A. (2000). Distribution and regulation of telencephalic aromatase expression in the zebra finch revealed with a specific antibody. J. Comp. Neurol. 423, 619-630.

Saldanha, C. J., Walters, B. J., and Fraley, G. S. (2010). Neurons that co-localize aromatase- and kisspeptin-like immunoreactivity may regulate the HPG axis of the Mallard drake (Anas platyrhynchos). Gen. Comp. Endocrinol. 166, 606-613.

Saleh, T. M., Connell, B. J., Legge, C., and Cribb, A. E. (2004). Stroke-induced changes in estrogen release and neuronal activity in the parabrachial nucleus of the male rat. J. Stroke Cerebrovasc. Dis. 13, 24-34.

Santa, T. (2011). Derivatization reagents in liquid chromatography/electrospray ionization tandem mass spectrometry. Biomed. Chromatogr. 25, 1-10.

Schlinger, B. A., Amur-Umarjee, S. Shen, P., Campagnoni, A. T., and Arnold, A. P. (1994). Neuronal and non-neuronal aromatase in primary cultures of developing zebra finch telencephalon. J. Neurosci. 14, 7541-7552.

Schlinger, B. A., and Arnold, A. P. (1992). Circulating estrogens in a male songbird originate in the brain. Proc. Natl. Acad. Sci. U.S.A. 89, 7650-7653.

Schlinger, B. A., and Arnold, A. P. (1993). Estrogen synthesis in vivo in the adult zebra finch: additional evidence that circulating estrogens can originate in brain. Endocrinology 133, 2610-2616.

Schmidt, K. L., Pradhan, D. S., Shah, A. H., Charlier, T. D., Chin, E. H., and Soma, K. K. (2008). Neurosteroids, immunosteroids, and the Balkanization of endocrinology. Gen. Comp. Endocrinol. 157, 266-274. 
Schmidt, K. L., and Soma, K. K. (2008). Cortisol and corticosterone in the songbird immune and nervous systems: local vs. systemic levels during development. Am. J. Physiol. Regul. Integr. Comp. Physiol. 295, R103R110.

Schumacher, M., Liere, P., Akwa, Y., Rajkowski, K., Griffiths, W., Bodin, K., Sjövall, J., and Baulieu, E.-E. (2008). Pregnenolone sulfate in the brain: a controversial neurosteroid. Neurochem. Int. 52, 522-540.

Scott, A. P., and Ellis, T. (2007). Measurement of fish steroids in water-a review. Gen. Comp. Endocrinol. 153, 392-400.

Soldin, S. J., and Soldin, O. P. (2009). Steroid hormone analysis by tandem mass spectrometry. Clin. Chem. 55, 1061-1066.

Soma, K. K. (2006). Testosterone and aggression: Berthold, birds and beyond. J. Neuroendocrinol. 18, 543-551.

Soma, K. K., Alday, N. A., Hau, M., and Schlinger, B. A. (2004). Dehydroepiandrosterone metabolism by 3ß-hydroxysteroid dehydrogenase/ $\Delta 5-\Delta 4$ isomerase in adult zebra finch brain: sex differences and rapid effect of stress. Endocrinology 145, 1668-1677.

Soma, K. K., Scotti, M.-A., Newman, A. E. M., Charlier, T. D., and Demas, G. E. (2008). Novel mechanisms for neuroendocrine regulation of aggression. Front. Neuroendocrinol. 29:476-489. doi: 10.1016/j.yfrne.2007.12.003

Soma, K. K., Sinchak, K., Lakhter, A., Schlinger, B. A., and Micevych, P. E. (2005). Neurosteroids and female reproduction: estrogen increases $3 \beta$ HSD mRNA and activity in rat hypothalamus. Endocrinology 146, 4386-4390.

Soma, K. K., and Wingfield, J. C. (2001). Dehydroepiandrosterone in songbird plasma: seasonal regulation and relationship to territorial aggression. Gen. Comp. Endocrinol. $123,144-155$.

Sorrells, S. F., and Sapolsky, R. M. (2009). The stressed CNS: when glucocorticoids aggravate inflammation. Neuron 64, 33-39.

Stanczyk, F. Z., and Clarke, N. J. (2010). Advantages and challenges of mass spectrometry assays for steroid hormones. J. Steroid Biochem. Mol. Biol. 121, 491-495.

Stoffel-Wagner, B. (2001). Neurosteroid metabolism in the human brain. Eur. J. Endocrinol. 145, 669-679.

Takase, M., Ukena, K., Yamazaki, T., Kominami, S., and Tsutsui, K. (1999). Pregnenolone, pregnenolone sulfate, and cytochrome P450 side-chain cleavage enzyme in the amphibian brain and their seasonal changes. Endocrinology 1936-1944.

Taves, M. D., Gomez-Sanchez, C. E., and Soma, K. K. (2011). Extraadrenal glucocorticoids and mineralocorticoids: evidence for local synthesis, regulation, and function. Am. J. Physiol. Endocrinol. Metab. 301, E11-E24.

Taves, M. D., Schmidt, K. L., Ruhr, I. M., Kapusta, K., Prior, N. H., and Soma, K. K. (2010). Steroid concentrations in plasma, whole blood and brain: effects of saline perfusion to remove blood contamination from brain. PLOS ONE 5, e15727. doi: 10.1371/journal.pone.0015727

Telepchak, M. J., August, T. F., and Chaney, G. (2004). Forensic and Clinical Applications of Solid Phase Extraction. Totowa: Humana.

Tokuda, K., Izumi, Y., and Zorumski, C. F. (2011). Ethanol enhances neurosteroidogenesis in hippocampal pyramidal neurons by paradoxical NMDA receptor activation. J. Neurosci. 31, 9905-9909.
Toran-Allerand, C. D., Tinnikov, A. A., Singh, R. J., and Nethrapalli, I. S. (2005). 17 $\alpha$-Estradiol: a brainactive estrogen? Endocrinology 146, 3843-3850.

Tsutsui, K., Ukena, K., Usui, M., Sakamoto, H., and Takase, M. (2000). Novel brain function: biosynthesis and actions of neurosteroids in neurons. Neurosci. Res. 36 261-273.

Vallée, M., Rivera, J. D., Koob, G. F., Purdy, R. H., and Fitzgerald, R. L. (2000). Quantification of neurosteroids in rat plasma and brain following swim stress and allopregnanolone administration using negative chemical ionization gas chromatography/mass spectrometry. Anal. Biochem. 287, 153-166.

von Schoultz, E., Bixo, M., Bäckström T., Silfvenius, H., Wilking, N., and Henriksson, R. (1990). Sex steroids in human brain tumors and breast cancer. Cancer 65, 949-952.

Wang, M.-D., Wahlström, G., and Bäckström, T. (1997). The regional brain distribution of the neurosteroids pregnenolone and pregnenolone sulfate following intravenous infusion. J. Steroid Biochem. Mol. Biol. 62, 299-306.

Wang, Y., Karu, K., and Griffiths, W. J. (2007). Analysis of neurosterols and neurosteroids by mass spectrometry. Biochimie 89, 182-191.

Washburn, B. E., Morris, D. L., Millspaugh, J. J., Faaborg, J., and Schulz, J. H. (2002). Using a commercially available radioimmunoassay to quantify corticosterone in avian plasma. Condor 104, 558.

Wingfield, J. C., and Farner, D. S. (1975). The determination of five steroids in avian plasma by radioimmunoassay and competitive proteinbinding. Steroids 26, 311-321.

Wong, S., Dykstra, M., Campbell, J. M., and Earley, R. L. (2008). Measuring water-borne cortisol in convict cichlids (Amatitlania nigrofasciata): is the procedure a stressor? Behaviour 145, 1283-1305.

Wynne, R. D., Walters, B. J., Bailey, D. J., and Saldanha, C. J. (2008). Inhibition of injury-induced glial aromatase reveals a wave of secondary degeneration in the songbird brain. Glia 56, 97-105.

Yu, L., Romero, D. G., Gomez-Sanchez C. E., and Gomez-Sanchez, E. P. (2002). Steroidogenic enzyme gene expression in the human brain. Mol. Cell. Endocrinol. 190, 9-17.

Zwain, I. H., and Yen, S. S. C. (1999). Neurosteroidogenesis in astrocytes, oligodendrocytes, and neurons of cerebral cortex of rat brain. Endocrinology 140, 3843-3852.

Conflict of Interest Statement: The authors declare that the research was conducted in the absence of any commercial or financial relationships that could be construed as a potential conflict of interest.

Received: 10 July 2011; paper pending published: 03 August 2011; accepted: 06 September 2011; published online: 26 September 2011.

Citation: Taves MD, Ma C, Heimovics SA, Saldanha CJ and Soma KK (2011) Measurement of steroid concentrations in brain tissue: methodological considerations. Front. Endocrin. 2:39. doi 10.3389/fendo.2011.00039

This article was submitted to Frontiers in Neuroendocrine Science, a specialty of Frontiers in Endocrinology.

Copyright (C) 2011 Taves, Ma, Heimovics, Saldanha and Soma. This is an openaccess article subject to a non-exclusive license between the authors and Frontiers Media SA, which permits use, distribution and reproduction in other forums, provided the original authors and source are credited and other Frontiers conditions are complied with. 